\title{
The everyday work of the drug treatment practitioner: The influence and constraints of a risk-based agenda
}

\begin{abstract}
Crime reduction is a key objective in drug treatment policy and practice, and the criminal justice system is a key player in the delivery of treatment, particularly its potential to provide a pathway into drug treatment. Despite cultural, ideological and philosophical differences, criminal justice and health sector workers are expected to work together alongside other agencies to address dependent drug use and associated harms. Through an analysis of indepth interviews with drug treatment practitioners this paper critically examines a number of assumptions underpinning this policy imperative. The author illustrates how the goals and everyday activities of drug workers have become aligned to the CJS helping to create closer working relationships between these two agencies. However, also argued is how such changes may have helped to constrain drug workers' relationships with other health and social care agencies making it difficult to address the complex needs presented by dependent drug users.
\end{abstract}

\section{Keywords}

Crime reduction, drug policy, multi-agency working, drug treatment, risk, risk management

\section{Introduction}

The emergence of 'risk' as a framework to be applied across a whole range of areas has been identified as a significant part of late modernity (Beck, 1992) that has led to new policy predicaments and responses. English drug policy appears as one of these areas. Identified as a 'risk', illicit drug use and drug users have become the subject of a proliferation of government-led drug strategies and interventions which aim to reduce, for example, so-called drug-driven offending (in other words, where the offence is committed solely to pay for 
drugs). While a number of explanations have been put forward for such changes (Seddon, Ralphs, and Williams, 2008) the literature appears to have paid relatively little attention to the practical implementation and operation of current drug policies, particularly with regards to the 'everyday work' of the drug treatment practitioner. Taking as its focus a group of drug treatment practitioners working in the North West of England this paper seeks to consider the consequences of a risk-based drug policy on their practice and, ultimately, the treatment experiences of drug users.

\section{Background}

In 1997, the New Labour government placed partnership working at the centre of its modernisation agenda considering it a key technique for overcoming the fragmented and disjointed services previously provided in health, social care and criminal justice sectors (Merrell, 2009:34). As well as the potential benefits of reduced duplication, improvement in performance, and more flexible, responsive services, partnership working provided the opportunity to 'disperse' governmental responsibilities to local government and public services to specifically address the problems of 'disadvantaged groups' (Merrell, 2009:32).

One of these groups consisted of problematic drug users. Yet despite being represented as a New Labour technique, a multi-disciplinary approach to address the multi-faceted nature of drug use was suggested by the Advisory Council for the Misuse of Drugs (ACMD) as far back as 1982 and calls for this type of working have been consistent features of the drug policy and guidance that have been developed since (Her Majesty’s (HM) Government, 1998; 2002; 2008; National Treatment Agency, 2002; Department of Health (DoH), 2007). In 1995, Tackling Drugs Together (HM Government, 1995) reinforced the partnership approach to local drug strategy and commissioning through the creation of Drug Action Teams (DATs), comprising representatives from health, probation, police and local authorities; teams that were later instructed to amalgamate and pool resources with their Crime and Disorder Partnerships to 'provide the right framework to enable the more effective delivery of the crime reduction and drugs agendas' (Home Office, 2003:1). This move was underpinned by the 
1998 Crime and Disorder Act which placed a legal duty on criminal justice agencies, local authorities, voluntary and private sectors to work together to address such concerns.

The establishment of effective working relationships between drug treatment practitioners and the criminal justice system (CJS), therefore, became a particular focus. In an attempt to address so-called ‘drug-driven’ crime, initiatives such as Drug Treatment and Testing Orders (DTTOs) (replaced in 2005 by Drug Rehabilitation Requirements (DRRs)) were implemented. Also launched in 2003 were the Criminal Justice Intervention Programme (later renamed as the Drug Intervention Programme (DIP)). Collectively, the aims of these interventions were to identify and work with individuals that might benefit from advice, assessment and treatment before and after they come into contact with the CJS. Consequently, drug treatment agencies that were not previously aligned with the CJS were commissioned specifically to deliver such interventions in order to 'direct drug misusing offenders out of crime and into treatment' (Home Office, 2004: 29).

It is not surprising then that several commentators contend that English drug policy has become crime-focused and that criminal justice has displaced health from its former dominant position. According to Stimson (2000:259-60) Britain’s once 'healthy' policy, which aimed 'to help problem drug users lead healthier lives', has given way to an 'unhealthy' 'war', which has 'focused down on the link between drugs and crime' leading to 'the introduction of a punitive and coercive ethos'. Harman and Paylor (2002:8) point to 'a strategic shift in the focus on national drug policy' arguing that the health-oriented harm reduction efforts of the 1980s have been displaced by a preoccupation with crime while Hunt and Stevens (2004:338) suggest that the so-called 'coercive shift of drug policy threatens to subordinate the focus of drug treatment agencies on the health problems of their clients to the aims of other organisations who are charged with protecting against other harms to the wider population'. Similarly, Duke (2006:413) maintains that drugs work is 'increasingly... being usurped under the heading of crime prevention' as 'the drug problem' has 'become increasingly framed and managed' as a 'crime problem'. 
Proponents of the 'criminalisation thesis' often campaign for drug policy to be re-oriented towards a public health approach concerned with helping users, preventing the spread of disease and enhancing well-being. However, alternative explanations for the apparent transformation in English drug policy are cautious about this proposal. In an analysis of the genealogy of drug policy over the last 150 years, Seddon (2010) presents evidence of continuity rather than change suggesting that public health approaches are closely intertwined with the so-called criminalisation of drug policy. He suggests that the foundation for contemporary drug policy has its roots in public health and the so-called liberal 'British system' of the 1920s was built on a 'medico-legal alliance' (Berridge, 1999:278) rather than a medical approach prevailing over a criminalising one. Seddon (2010) also considers the public health response to HIV in the 1980s as not too dissimilar from the crime-focused agenda of later years. Both, he suggests, are based on a shared view that the 'drug problem' is a risk to society, whether in relation to 'a real contagious disease (HIV), or criminal victimisation - which needs to be monitored, controlled and managed' (Seddon, 2011:417). Shiner (2013) offers similar insights suggesting that the plethora of initiatives, including 'coerced' treatment, are simply symptoms of broader criminal justice trends and not the displacement of health in favour of crime reduction practices.

There is a widely-held view that English drug policy is, yet again, in the throes of major transformation. Whereas drug policy implemented in the 2000s seemed to have been underpinned by a crime reduction agenda, over the last five years this focus appears to have receded as a new recovery agenda - the reorientation of local treatment provision towards 'full recovery' by offering people more abstinence based support - has emerged (HM Government, 2010; 2012). However, some are unconvinced that such changes represent a paradigm shift. Seddon, Williams and Ralphs (2012) suggest that this direction in drug policy retains much in common with the previous crime-focused strategy, and the earlier public health approach. Under this 'new' direction, the authors argue, drug users are still viewed as a source of risk to society; previously it was in terms of their capacity to commit crime, now it 
is in terms of them being a burden on the economy by drawing benefits and failing to contribute as a tax-payer. Similarly, Duke (2013:1) suggests 'although the moves toward a recovery-based policy represent significant changes, there are powerful continuities and remnants of previous policies and structures, which have endured and set the parameters for the current policy framework'. There has not necessarily been a 'shift' in English drug policy but rather a 'reframing' of English drug policy that reflects changing political agendas.

Despite the various political agendas that have shaped English drug policy, the CJS remains a key player in the provision of drug treatment (Duke, 2013) and is expected to work, alongside drug treatment providers, with other health and social care agencies to address dependent drug use and associated harms - a policy imperative that is underpinned by two main assumptions. The first is that the alignment of the CJS, drug treatment and other health and social care services will help to overcome the fragmented and disjointed services previously provided by these sectors (HM Government 1998; 2002; 2008; 2010). The second is that such partnership working will help to identify and eradicate a range of risk factors (including drug use and other complex needs presented by drug userss) that underpin offender criminal behaviour (Seddon, et al. 2012). Yet when investigating the impact of the ever closer alignment between drug treatment practitioners and the CJS on their working relationships and practice, the evidence from the literature remains inconclusive.

Policy changes promoting criminal justice diversion to treatment are not typically followed by support. Despite the arguments that such changes might result in cost savings, concerns about civil liberties raised by punitive and coercive practices remain (Wild, 1999). Similarly, Weston (2014) argues that the 'reframing' of drug policy has resulted in the articulation of inconsistent messages that may have reinforced the polarised treatment ideologies observed among professionals working with drug users. The implementation of DTTOs encountered many of these difficulties with cultural, ideological and philosophical differences found between treatment and criminal justice staff resulting in fundamental problems around interagency working between the two groups (Turnbull, et al. 2000; Hough, et al., 2003). The 
entrenched institutional interests of the health-oriented agencies around care, health and harm reduction clashed with the coercive and punitive based ethos of the CJS. There were points of conflict between the requirements of the CJS and drug treatment around issues of confidentiality and information sharing (Barton and Quinn, 2002). The CJS appeared inflexible and tended to be focused on the duration of sentence while treatment services recognised the relapsing nature of dependent drug use and the long-term recovery periods required. Difficulties of this nature were also evident in the implementation of DRRs with treatment staff concerned that the CJS was not an effective motivator to engage in drug treatment (Best, et al. 2010).

Evidence of this kind calls into question the extent to which drug treatment practitioners can be allied to the CJS, yet competing evidence suggests that this type of resistance is not widespread. McSweeney et al (2007) reported accounts of good working relations between health and criminal justice professionals and noted the support that drug workers gave to the enforcement aspects of DTTOs, suggesting that testing assisted 'staff in identifying causes of behaviour change and work towards possible solutions' (McSweeney, et al., 2008:43).

It is clear that the drug treatment practitioner must act on an amalgam of rationales oscillating around, but also beyond, the caring and harm reductionist ethos of health and social services and the more coercive and punitive based ethos of the CJS yet the impact of these dichotomous roles and responsibilities have not been explored in great detail. Drawing on the perspectives of drug workers this article critically examines some of the assumptions underpinning the alignment of criminal justice, drug treatment and other health and social care services. The extent to which fragmented and disjointed services have been overcome and the complex needs of drug users addressed will be evaluated. Specific attention is paid to how a risk-based drug policy agenda may have influenced the perspectives of drug workers regarding their goals and the implications these influences have had on their 'everyday practice'. The implications on the quality of treatment received by drug users are also considered. 


\section{Methodology}

The research presented in this paper draws on fieldwork conducted during 2009-2011 as part of an ESRC funded doctoral project. The key aim of this project was to explain why, despite the development of a series of drug strategies (HM Government, 1995; 1998; 2002; 2008; 2010) and vast increases in funding, drug users were still struggling to receive the services they require to address their diverse problems (Buchanan, 2010). Underpinning this aim was the need to understand the implications of drug policy, which had adopted a framework of risk-based strategies to control drugs and drug users, on drug treatment practice and the treatment journeys of drug users.

Like other research that has examined the effects of externally imposed policy transitions on professional identities (Artaraz, 2006:910) this paper draws on the conceptual tools of 'field' and 'habitus' developed in Bourdieu's (1977) theory of practice. According to Bourdieu (1998:32), 'field' is the setting in which agents are located and consists of forces, whose necessity is imposed on agents who are engaged in it, and struggles, within which agents confront each other with differentiated means according to their position within the 'field'. From a Bourdieusian perspective, therefore, 'drug treatment' may be conceived of as a 'field', in which agents from health, social care and the CJS are located. This field consists of both forces, such as changing political agendas, which are imposed on the various professionals working within it and, potentially, struggles whereby inter-professional relationships are tested. 'Habitus', on the other hand, is 'an acquired system of generative schemes objectively adjusted to the particular conditions in which it is constituted' (Bourdieu, 1977:95), or as Stone (2008:33) explains, a process of 'routine osmosis' where action is developed through a gradual absorption within certain fields and become regularised patterns of behaviour as a result. As a consequence of this process Bourdieu suggests that the 'field' often becomes a site of struggle in which various actors compete over, contest, and construct influence and power. Conflicts of this type might involve drug treatment workers taking on responsibility 
for activities that are not traditionally considered 'drugs work'. As Hunter (2003:326) claims, individual identities are 'fluid and constantly in flux, dependent on the social, political, economic and ideological aspects in which individuals find themselves in'. Therefore, not only do conflicts result in drug workers taking on new priorities but their identities and ‘everyday practice’ may also be profoundly affected. While no theoretical claims are made in this paper, these concepts allow for the consideration of changes in the drug treatment field at a broader level while also helping to explain the ways in which behaviour and experience, and thus ‘everyday practice', are moulded as a consequence of such changes (Bourdieu, 1989:14).

To generate an understanding of the 'everyday practice' and perspectives of drug treatment workers this paper draws on 20 face-to-face semi-structured interviews with drug treatment providers, made up mainly of substitute prescribing services, and other professionals across two towns in the North of England, referred to 'West Town' and 'East Town' in this paper. This sample was partly selected from a set of 26 interviews done with drug users attending treatment services where they were asked to identify individuals they thought had made an impact on their treatment journey so extracts from these interviews are also used in this paper. Where professionals from agencies were not identified and sufficiently represented, interviewees were selected using the author's own network of contacts from previous research. Where extracts from interviews are presented pseudonyms have used to protect the identity of participants.

In accordance with a grounded theory approach the initial process of analysis, was to thematically code the interview transcriptions by becoming familiar with the content, and looking for patterns and themes that helped to make sense of the data. However, as acknowledged by Bourdieu and Wacquant (1992:35), every act of research is simultaneously empirical and theoretical: 'even the most detailed empirical operation, such as a coding decision or the inclusion of an item in an interview schedule, involves theoretical choices'. Therefore, by drawing on the conceptual tools of 'field' and 'habitus', the analysis also included a degree of analytical induction. To more thoroughly understand the 'everyday 
practice' the analysis involved paying particular attention to the different and changing roles, responsibilities and activities engaged in by drug treatment practitioners, covering also their perceptions of the aims of drug treatment. In line with a Bourdieusian framework, the analytical lens was also focused on the drug treatment practitioners' working relationships with both CJS and other health and social care agencies, including their knowledge of other services, processes of communication and information sharing arrangements. Not only did this analytical focus help to shed light on the plight of drug treatment practitioners who find themselves working across organisational boundaries but also enabled a critical examination of the assumptions, outlined earlier, that underpin the strategic imperative to coalesce drug treatment, the CJS and other health and social care services.

To support this critical examination, an analysis of the treatment journeys of drug users, including their treatment experiences, the services they were referred to and subsequently engaged with, was also done. To investigate how the journeys of those referred into treatment by the CJS differed from those referred from elsewhere treatment journeys were compared according to their source of referral.

Much of the earlier work examining partnership working between drug treatment practitioners and the CJS documented competing accounts about their working relationships. Over a decade since the implementation of interventions such as DTTOs, DRRs and DIP the data presented below helps to clarify this matter by not only illustrating how the working relationships between criminal justice and drug treatment staff have improved but also considers the implications of this on the 'everyday practice' of drug workers and the treatment received by drug users.

\section{Achieving coherence between criminal justice and drug treatment work}

The initial resistance to the drugs-crime agenda, found in the opinions of drug workers during the DTTOs evaluation (Turnbull, et al, 2000) was not widespread in the opinions of those interviewed for this study. While drug workers recognised the need to help clients "reduce 
their drug use, or with housing or employment issues” [Graham, Substance Misuse Practitioner] most of them also acknowledged the priority to reduce crime. Margie, a substance misuse practitioner, asserted that:

“Even if it’s just some little step forward, somebody not offending every day, I’ve got one lass, she's not offended for a whole week and we've got her down from four or five times a day. To me that's a real buzz”.

Similarly, Bill, a substance misuse liaison practitioner acknowledged that his views regarding the priorities of drugs work had changed:

“I’ve amended my views I suppose, now I think we're achieving great things if we can stop somebody from offending”.

And Mike, a substance misuse service manager, explained that while crime reduction may not initially be regarded an aim of drug treatment, it is at least compatible with other aims and remains one of the main priorities for drug treatment:

\footnotetext{
"You have to accept that reducing re-offending is king in the world of drug treatment, it has been for many years ... I am a believer in the benefits of treatment, if you deliver the right kind of treatment you will see reductions in drug use, improvements in mental functioning, physical health, social functioning, including a reduction in offending. So I can live with it”.
}

Comments of this kind represent a departure from the resistance documented in the early years of criminal justice interventions. Despite suggestions that 'particular agencies and individuals will tend to promote one aspect [of drug use] at the expense of another depending upon their philosophical viewpoint' (Buchanan, 2010:124) the evidence presented here suggests that the priorities of the drug worker are no longer limited to the aims found in health and social care. A reduction in offending has become regarded as a key indicator of the success of drug treatment suggesting an adjustment of opinions cohering with traditionally criminal justice concerns. 
There was also evidence of a shift in the 'everyday practice' of drug workers, which was becoming increasingly aligned with those of the CJS. While drug workers are often trained to deliver psychosocial interventions, working within a CJS framework that aims to reduce socalled drug-driven offending has refocused their attentions on criminal justice type activities such as monitoring. The drug treatment practitioners interviewed for this study confirmed that much of their core activities were about recording and processing data about their client group:

"We want to provide a quality service but we are also responsible for monitoring. So every three months we'll do a Treatment Outcomes form, that's every six times you see a client, then you've got your urines on top of that, plus your doctors reviews, so there's something else that's more important than sitting down with your client and working with them”. (Beverly, Substance Misuse Practitioner)

"I find the admin side and recording has become bigger than the job”. (Tim, Substance Misuse Practitioner)

Some workers commented on how records, once regarded as confidential, were now used, and even partly created, to help criminal justice agencies make decisions about particular clients:

"The clients here are required to attend, as part of the court order, and once they buy into being on a court order we have to share with the probation service whether people are attending, whether they're using on top and our views about how people are progressing. There isn't the same confidentiality arrangement that there once was”. (Graham, Substance Misuse Practitioner)

As the priorities and 'everyday work' of drug treatment practitioners and the CJS have become aligned so too have the working relationships between the two agencies improved:

"When I first came into this role it was almost a constant battle, with probation especially. But over the years, I think we have worked together really well and we've developed some very good working relationships. I honestly think we have good working relationships with probation, the court and the police”. (Ann, DIP Manager) 
“We've got pretty good relationships with a couple of the prisons because they're used to seeing our faces or speaking to us”. (Sarah, Criminal Justice Treatment Worker)

Drug workers and criminal justice workers regularly communicate using a variety of approaches including meetings and informal conversations by telephone and email, suggesting an openness and informality that can only be achieved through good working relationships, as Margie and Karen described:

"The lead for offending is obviously probation but we do three way meetings where we sit down with the client and draw up a joint care plan. Certainly, there isn’t a week goes by when I don't hear from every single one of the probation officers in the team I work with, often two or three times a day”. (Margie, Substance Misuse Practitioner)

"Probation tend to be quite good in that they're always ringing us to see if they've attended”. (Karen, Substance Misuse Practitioner)

Rather than being fragmented and disjointed, services provided by the CJS and drug treatment have become aligned so much so that, while drug workers have retained some of their more traditional priorities around harm reduction, emphasis on 'individual care' appears to have been overshadowed by traditionally criminal justice concerns. The priorities of crime reduction and engagement in criminal justice type activities, such as recording and processing data about their clients, have become what Stone (2008:33) refers to as "regularised" treatment aims and practice of drug workers, as one police sergeant remarked:

"Our pledge is to reduce crime and this [drug treatment] is a crime reduction tool ... the one thing that everybody's trying to do, whatever your agency is, is to reduce crime”

As Seddon, Williams and Ralphs (2012:124) acknowledge, much of drug workers' everyday work has become 'concerned with the creation, production, processing, interpretation, distribution, sharing, reception or utilisation of knowledge or information'. 
While the alignment between drug treatment practitioners and the CJS seems to have had a positive effect on their working relationships the evidence emerging from this study suggests that it has nevertheless 'constrained' the practice of 'everyday drugs work'. By considering the quality of partnership working between drug treatment practitioners and other health and social care agencies, and the levels of support received by drug users, the remainder of this paper sets out to demonstrate how.

\section{One worker's coherent practice is another worker's constrained practice}

Although aims to reduce offending may not be incompatible with the various other aims of drug treatment, as Wardle (2008:3) suggests, by responding to a strong national lead '...the growing alignment with criminal justice has actually only served to further isolate the drug treatment field from other related health and social care sectors delivering care and support to socially excluded'.

Evidence of this isolation was found in the accounts of drug workers with some lacking knowledge about the various services available and others complaining about ambiguous referral processes. Not only do these issues suggest significant problems about the way drug treatment practitioners collaborate and communicate with other health and social care services but allude to a formality in communication processes that were not apparent in their relationships with the CJS.

Unlike their understanding about criminal justice systems and matters there was a general lack of knowledge about who provides support for mental health, housing, education and employment. Although West Town had the benefit of a dual diagnosis service, dedicated to the treatment of combined substance misuse and mental illness, when Beverley, a substance misuse practitioner of five years, was asked about services for mental disorder she referred her clients instead to their General Practitioners (GPs):

"I would suggest that would be the doctor...there's nobody specific, not that I'm aware of”. 
Drug workers' lack of knowledge about the dual diagnosis service in West Town was reflected in the types of referrals received by them, as Phil, the dual diagnosis nurse, explained:

"The majority of referrals come from in-patient psychiatry... The next largest group is community or mental health services, then primary care and GPs and the occasional health visitor or specialist midwifery. Then the next group is substance misuse services"

There was also lack of knowledge about the types of agencies that provide housing, educational and employment services. Bill explained how he had used such services in the past but was unaware of what was available in more recent years:

"We did have a woman that works for the College...Now whether it's still going or not, I don’t know"

The referral processes and assessment criteria of other health and social services were also unknown. Many drug workers complained about the lack of clarity regarding the referral process to the Community Mental Health Team (CMHT). When concerned about the mental health of one of his clients Bill was unable to process a successful referral to the CMHT:

\footnotetext{
"We had a guy who was referred to the CMHT because he was talking about suicide. I'm a psychiatric nurse, so I'm not immediately going to get panicky about it... but at the time his mother had died and I referred him to the CMHT and they said he didn't meet their criteria. What's your criteria? Could I find out what their criteria was, no... I reckon if you asked any drug worker here today, how do you refer somebody to psychological services, they won't be able to tell you and I don't know"
}

Similarly Sarah, a criminal justice treatment worker, expressed confusion about the referral criteria for the CMHT: 
“I find it a little bit confusing, I'm never too clear about how to get somebody some help, and I have made referrals a few times to the CMHT but never had one of my clients taken on to their caseload”.

As a consequence, there was some concern among workers that their clients were not being treated for their mental health problems:

“Are we just patching hands up here by giving them a substitute drug but not being able to deal with the psychological element of it? I think a lot of them have got psychological problems, deep-seated, that have never been dealt with...and one of the reasons for this is that the drug worker doesn't know how to refer them”. (Bill, Substance Misuse Liaison)

The referral processes of housing providers were also unknown as Bill, again, explained:

“I’ll be honest, I really don’t know what [the housing providers] do. I know what they’re supposed to do but I don’t know how it works or what their expectations are”.

The focus on crime reduction (or reductions in risk) and engagement in criminal justice type activities, such as recording and monitoring information about their clients, has guided and constrained drug workers' 'everyday practice' to such an extent that, beyond 'doing the basics”, they no longer have time to engage in 'meaningful' work with their clients, including seeking referrals and follow-up. While the referral processes of CMHTs and housing providers may be described as opaque to all those working outside of these contexts the literature suggests that this problem can be overcome through the establishment of closer working relationships (Chew-Graham, et al. 2007; Trevellion, et al. 2012). Yet making 'knowledge work' (Seddon, Williams and Ralphs, 2012) the core activity of drug workers has constrained their 'everyday practice' resulting in less time available to not only establish such relationships but also to determine the procedures of other health and social care services. Graham, a substance misuse worker of 6 years and previously a probation officer remarked: 
“There's a lot of bureaucracy and there are some parts of the role, which are things that you do have to do and I've got to a point where I'm just doing those basics. I think all of our clients need a lot more support than I personally give them ...I think in practice the drug service is under a huge amount of pressure in terms of statistical returns and meeting certain targets and clients needs aren't necessarily what everybody’s focusing on”

As Wardle (2008) predicted, the alignment between criminal justice and drug treatment has fostered closer working relationships between these two agencies but constrained the working relationships between drug treatment and other health and social care agencies. Not only does this evidence undermine the assumption that the alignment of the CJS and drug treatment will help to overcome the fragmented and disjointed services provided for in these sectors, but raises questions also about the extent to which this partnership will help to address the complex needs presented by drug users.

\section{Addressing the complex needs presented by drug users}

Despite concerns raised by drug workers that drug users were not receiving treatment for their mental health problems, this was not always the case. West Town, for example, provided a service for mentally disordered offenders who had needs relating to drugs and alcohol. For drug workers who deal with criminal justice clients, a referral to this team was sufficient to make an appointment for assessment, as Tim explained:

\footnotetext{
"Yes, the [criminal justice mental health team] is specifically criminal justice, so people would have to have some sort of involvement in crime. Of course all of my clients would be coming out of prison so it's a simple referral... I can get a person seen within a week".
}

This system of referral contrasts sharply with those described in the previous section where the referral process of CMHTs was described as 'complicated', 'not so easy', and 'confusing'. 
Similarly, not all drug users received unsatisfactory support for their housing. In both East Town and West Town, individuals involved in the CJS were often assigned to a dedicated housing support worker. Mike, a drug service manager, explained how criminal justice clients often received more support for their housing needs:

\footnotetext{
“There's a housing worker who is attached to the DIP but he only deals with CJS clients. If you ask me what my suspicion is about the housing conditions in which many of our service users live, many of whom are not in contact with the CJS and will not be eligible for the DIP service, I don’t know what they're like”.
}

Although drug workers did not appear concerned about unacceptable inequalities in access to treatment, drug users involved in the CJS did appear to benefit from extra resources that were not available for their 'non-offending' counterparts. Not only did drug treatment services appear better equipped to address the problems of criminal justice clients but as Fiona, a detox nurse, describes they were also prioritised:

\footnotetext{
“There's a lot of pressure now, lots of targets, specifically on the criminal justice side, those clients get seen very quickly and they're always offered appointments”.
}

There are, of course, a number of unfortunate consequences of the apparent priority afforded to drug users involved in the CJS, which are illustrated by the experiences of those interviewed for this study. Using Wayne's experience the following discussion demonstrates the effectiveness of a DRR for him. However, it also shows the consequences of withdrawing support once such a requirement has been completed.

At his first interview Wayne was aged 39. He had been using substances since the age of 14 and had received numerous episodes of treatment, his latest one beginning five months earlier. At this point he was given a DRR and prescribed methadone. As part of his DRR, Wayne had to undertake two drug tests a week and attend a structured programme involving one to one and group work sessions: 
“Since I've got this order, my drug use has reduced tremendously and I come here more or less every day of the week"

In contrast to his previous treatment experiences Wayne described how his DRR worker appeared to have time for him:

\footnotetext{
"You just got a script and that was it, I used to pick my script up every fortnight, there was no counselling. The worker that I've got here, we have half an hour talk, she asks me everything, which I've never had before"
}

At this point, Wayne's treatment seemed to be going well and, with the extra support he was receiving by being on a DRR, he could envisage a future without drugs:

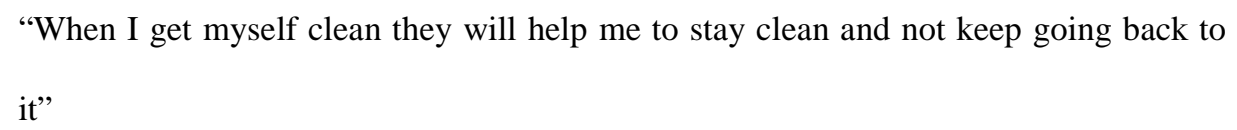

Yet at his second interview [five months later], after completing his DRR, Wayne relapsed. He explained that he began to worry about finances and was finding it difficult to cope without the support he received when subject to a DRR:

“Things have just started to crop up again and I need help to get it sorted out, otherwise I'm gonna end up either dead or bang at it again”

Unfortunately, Wayne’s experience was not exceptional. Reece also reported feeling unable to cope once his licence from prison had ended and, similarly, he too relapsed:
"It all sort of stopped, my mum left, my brother left and then all this [prison licence] stopped, so I ended up on my own. I just wanted to stay drug free and get on with my life and get a job. I was really happy with the help I was getting when I was on licence and coming here, doing groups and everything”

Due to the increased support given to drug users involved in the CJS many of those interviewed reported having specifically committed a crime to maintain the support they had as a criminal justice client, as Stuart explained: 
"I did go out and commit an offence on purpose to get a DRR. My head just went one day and I thought, I need help, I know it was the wrong way to go about doing it but I can't really come to the probation office and ask, can you put me on probation. The court was only gonna give me six months and I said to them that's not long enough, so they gave me 12 months”

These experiences demonstrate the vulnerability of drug users leaving the CJS. While subject to a DRR or prison licence the drug users interviewed for this study received an intense treatment programme that seemed to be addressing their complex problems. But once these orders were complete the support structure they had as criminal justice clients was withdrawn. Some drug users reported relapsing when their orders ended, others reported committing crime and getting arrested; a strategy that would guarantee their support was reinstated. Not only does this evidence the unacceptable inequalities in access to treatment but partly undermines the second assumption that the alignment of criminal justice and drug treatment will help to address the complex needs presented by drug users, as only when they are criminal justice 'clients’ did they receive support addressing such needs.

\section{Discussion and conclusions}

Multi-agency working is no doubt difficult in any field. However, the issues that have emerged from emphasising the social and economic costs caused by drug users have only added to this already difficult task. The focus of drug policy to break the so-called drugscrime link and promote greater involvement of the CJS in controlling drug use has constrained the practice of drugs 'work' within a framework that is both rigid and punitive, and relies on the regular production of data to monitor, control and manage individuals. While this direction may have led to the coherent practice of criminal justice and drug treatment work and improved working relationships between these two agencies it has nevertheless influenced and constrained the character of 'drugs work' in such a way that the fragmented and disjointed services previously identified in the sector and the need to address the complex needs of drug users remain significant challenges. 
Rather than the 'multi-disciplinary' approach, that was initially referred to by the ACMD (1982), the alignment between drug treatment practitioners and the CJS in terms of priorities and day-to-day activities, have not only served to confirm the 'medico-legal' alliance created more than a century ago but have also reduced the time available for the fostering of relationships with other health and social care professionals. Knowledge of services providing treatment or support for issues such as mental health, housing, and unemployment, and their referral pathways, was variable between the practitioners interviewed. Hence, those drug users that did not appear to be offending found it difficult to resolve problems relating to these issues.

Drug treatment services, that may previously have been defined as 'help', are now wrapped up in notions of punishment including a treatment protocol of required assessments and appointments, drug testing, and sanctions for breach of treatment rules that are more akin to the status of offender than a patient or client; a situation that very few agencies would have formerly tolerated but have had to accommodate for financial survival (McSweeney and Hough, 2006). Initially, drug workers voiced their unease about being allied to the CJS but appear to have resigned themselves to compliance by accepting their role in reducing crime and managing risk; this policy focus has, after all, resulted in a substantial investment in drug treatment worth about $£ 800$ million per year (National Treatment Agency (NTA), 2012:6).

These types of conclusions are consistent with those that have been reached in social work practice where commentators have suggested that 'developments in British social work have not been widely contested from within the occupation' (Jones, 1999:48). Yet, as Thomas and Davies (2005) argue, such an interpretation does not appreciate agency and difference within and between professionals and practitioners. Rather than treating resistance as an established set of acts and behaviours that are overt and visible, these authors suggest the need to appreciate the more subtle forms of resistance that may include subversive acts and behaviours, thus broadening out what counts as resistance (Thomas and Davies, 2005:727728). Consistent with this suggestion, the comments offered by the practitioner participants of 
this study illustrate how drug workers use varied ways to construct their everyday practice by reflecting and reinscribing the more traditional aims of the CJS of reducing re-offending as 'improvements in social functioning'. Therefore, by interrogating the 'everyday work' this paper demonstrates that in carrying out their duties, drug treatment practitioners are neither institutional 'dupes' nor wholly self-interested individuals but instead, as Nethercote (2014:1057) found in her study of local housing professionals, act in ways that 'are shaped by external realities, but also by their own subjective concerns and meanings'.

Nevertheless, the dual role that drug workers now have seems to have created the problems identified in this research. Time taken up by regulatory policing activities such as monitoring attendance meant that the drug treatment workers recruited to this study could not practically offer help with mental health, accommodation and debts. While the drug users of this study were able to resist these changes by negotiating access to appropriate forms of treatment through the CJS, the concern that some users may not be receiving help for their multiple needs remains. It is arguable then that a change of focus is required; not simply a reorientation back to a public health approach that is still focused on the risk caused by drug users and demands that 'knowledge work' (Seddon, Williams and Ralphs, 2012) remains the core of activity for drug workers, but one that is centred on meeting the various and complex needs that drug users have, regardless of their source of referral.

On a positive note this paper does show that despite the difficulties of multi-agency working it can be successfully implemented. Although the alignment of criminal justice and drug treatment was initially met with overt and visible forms of resistance this seems to have subsided as drug treatment practitioners negotiate and redefine their identities and 'everyday work' as being about both care and control, supporting the importance placed on relational identities in the social policy literature. As Hunter (2003:339) claims, relational identity emphasises connection, arising out of the recognition of differentiation, and it is these principles of social relationships that produce the possibility of working together amongst individuals who might not come from the same perspective but who can share a common 
purpose. However, to take multi-agency working to the level required to address the multiple needs presented by drug users, drug policy and commissioning arrangements need to focus on the integration of the drug treatment workforce into local community health and social care services. Only when such integration is achieved can a fully multi-disciplinary approach to the treatment of drug dependency be realised.

\section{References}

Advisory Council on the Misuse of Drugs (1982) Treatment and Rehabilitation, HMSO, London.

Artaraz, K. (2006) 'The wrong person for the job? Professional habitus and working cultures in Connexions’ Critical Social Policy 26(4): 910-931

Barton, A. \& Quinn, C. (2002), 'Risk Management of Groups or respect for the Individual? Issues for information sharing and confidentiality in DTTOs', Drugs: education, prevention and policy, 9(1):35-43.

Beck, U. (1992) Risk Society: Towards a New Modernity. New Delhi: Sage.

Berridge, V. (1999), Opium and the people: Opiate use and drug control policy in nineteenth and early twentieth century England, London: Free Association Books .

Best, D., Wood, K., Sweeting, R., Morgan, B., and Day, E. (2010) 'Fitting a quart into a black box: Keyworking in quasi-coercive drug treatment in England', Drugs: Education, Prevention and Policy, 17(4):370-387.

Bourdieu, P. (1977) Outline of a Theory of Practice, Cambridge: University Press.

Bourdieu, P. (1998) Practical Reason: On the Theory of Action, California: Stanford University Press

Bourdieu, P \& Wacquant, L.J.D. (1992) An Invitation to Reflexive Sociology, Cambridge: Polity Press 
Buchanan, J. (2010) "Understanding and misunderstanding problem drug use: working together" in R.

Chew-Graham, C., Slade, M., Montana, C., Stewart, M., and Gask, L. (2007) ‘A qualitative study of referral to community mental health teams in the UK: exploring the rhetoric and reality’, BMC Health Services Research, 7:17

Department of Health (England) and the devolved administrations (2007), Drug Misuse and Dependence: UK Guidelines on Clinical Management, London: Department of Health.

Duke, K. (2006), 'Out of crime and into treatment?: The criminalization of contemporary drug policy since Tackling Drugs Together', Drugs: Education, Prevention and Policy, 13((5):409415.

Duke, K. (2013) 'From crime to recovery: The reframing of British drugs policy', Journal of Drug Issues, 43(1):39-55.

Harman, K. and Paylor, I. (2002) 'A shift in strategy’, Criminal Justice Matters, 47(1):8-9.

Home Office (2003) Drug Action Team and Crime and Disorder Reduction Partnership Integration/Closer Working: Further Guidance. London: Crime Reduction Delivery Team / Partnership and Regions (Drugs Unit).

Home Office (2004) Reducing Re-offending National Action Plan, London: Communication Directorate.

HM Government (1995) Tackling drugs together: A strategy for England 1995-1998 London: HMSO

HM Government (1998) Tackling drugs to build a better Britain: The government's ten year strategy for tackling drug misuse London:HMSO.

HM Government (2002) Updated Drug Strategy 2002, London: Home Office.

HM Government (2008) Drugs: protecting families and communities, The 2008 drug strategy, London: Home Office. 
HM Government (2010) Drug Strategy 2010 Reducing Demand, Restricting Supply, Building Recovery: Supporting People to live a Drug Free Life, London: Home Office.

HM Government (2012) Putting Full Recovery First, London: Home Office.

Hough, M., Clancy, A., McSweeney, T. \& Turnbull, P.J. (2003) The Impact of Drug Treatment and Testing Orders on Offending: Two Year Reconviction Results. Home Office Research Findings 184. London: Home Office.

Hunt, N. and Stevens, A. (2004) 'Whose harm? Harm reduction and the shift to coercion in UK drug policy’, Social Policy and Society, 3(4):333-342.

Hunter, S. (2003) 'A critical analysis of approaches to the concept of social identity in social policy’, Critical Social Policy, 23(3):322-344

Jones, C. (1999) 'Social Work: Regulation and Managerialism’, in M. Exworthy and S. Halford (eds) Professionals and the New Managerialism in the Public Sector. Buckingham: Open University Press.

McSweeney, T. \& Hough, M. (2006) 'Supporting offenders with multiple needs: Lessons for the "mixed economy" model of service provision', Criminology and Criminal Justice, 6(1):107125.

McSweeney, T., Stevens, A., Hunt, N., and Turnbull, P. (2007) 'Twisting arms or helping hand? Assessing the impact of coerced and comparable voluntary drug treatment options', British Journal of Criminology, 47(3):470-490.

McSweeney, T., Stevens, A., Hunt, N., and Turnbull, P. (2008) 'Drug testing and court review hearings: uses and limitations’, Probation Journal, 55(1):53-67.

Merrell, J. (2009) 'Promoting inclusive partnership working', in R. Carnwell \& J. Buchanan, (2010) Effective Practice in Health, Social Care and Criminal Justice: A Partnership Approach, Maidenhead: Open University Press. 
National Treatment Agency \& Department of Health (2002), Models of care for the treatment of drug misusers: promoting quality, efficiency and effectiveness in drug misuse treatment services in England, London: NTA.

Nethercote, M. (2014) 'Reconciling policy tensions on the frontlines if indigenous housing provision in Australia: Reflexivity, resistance and hybridity’, Housing Studies 29(8):1045-1072 Seddon, T. (2010), A History of Drugs, Abingdon: Routledge.

Seddon, T. (2011), 'What is a problem drug user?' Addiction Research and Theory, 19(4):334343.

Seddon, T., Ralphs, R., \& Williams, L. (2008), "Risk, Security and the 'Criminalization' of British Drug Policy", British Journal of Criminology, 48(6):818-834.

Seddon, T., Williams, L. \& Ralphs, R. (2012) Tough Choices: Risk, Security and the Criminalization of Drug Policy, Oxford: Oxford University Press.

Shiner, M. (2013) 'British drug policy and the modern state: Reconsidering the criminalisation thesis’, Journal of Social Policy, 42:623-643.

Stimson, G.V. (2000) 'Blair Declares War: the unhealthy state of British drug policy', International Journal on Drug Policy 11(4):259-264.

Stone, R. (2008) Key Sociological Thinkers, 2nd Ed, Basingstoke: Palgrave Macmillan.

Thomas, R. \& Davies, A. (2005) 'What have the feminists done for us? Feminist theory and organisational resistance’, Organisation 12(5):711-740

Trevellion, K., Howard, L.M., Morgan, C., Feder, G., Woodall, A., \& Rose, D. (2012) 'The response of mental health services to domestic violence: A qualitative study of service users' and professionals' experiences', Journal of the American Psychiatric Nurses Association 18(6):326-336

Turnbull, P. J., McSweeney, T., Webster, R., Edmunds, M., \& Hough, M. (2000), Drug Treatment and Testing Orders: Final evaluation report, London: Home Office.Unell, I. (2002) 
'Controlling drug use: where is the justice?' in D. Ward, J. Scott \& M. Lacey (eds) Probation Working for Justice, Oxford: Oxford University Press.

Wardle, I. (2008) The Strategic Isolation of the British Drug Field and the new Recovery Philosophy, available from http://www.fead.org.uk/docs/Ian-Wardle_The-strategic-isolationof-the-drugs-field.pdf [accessed $4^{\text {th }}$ December 2011].

Weston, S. (2014) 'The origins of conflict in dependent drug treatment: Lessons for partnership working’, British Journal of Community Justice, 12(1):9-26

Wild, T.C. (1999) 'Compulsory substance-user treatment and harm reduction: A critical analysis', Substance Use and Misuse, 34(1):83-102. 